\title{
Matrix Consolidation Mechanism in 1D-Ti/SiC/C Composites Produced by Continuous Binder-powder Coating
}

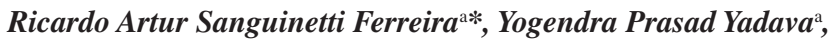
Jean Michel Quenisset ${ }^{\mathrm{b}}$, Corinne Arvieu ${ }^{\mathrm{b}}$

\author{
aDepartamento de Engenharia Mecânica, Universidade Federal de Pernambuco - UFPE, \\ Av. Acadêmico Hélio Ramos, s/n, CEP 50740-530, Recife, PE, Brasil \\ ${ }^{\mathrm{b}}$ Institut de Chimie et de la Matière Condensée de Bordeaux - ICMCB-CNRS, \\ Av. du Dr. Schweitzer, 33608 PESSAC Cedex, France
}

Received: October 22, 2010; Revised: October 5, 2012

\begin{abstract}
In this work matrix consolidation mechanism has been investigated in $1 \mathrm{D}-\mathrm{Ti} / \mathrm{SiC} / \mathrm{C}$ composites produced by Continuous Binder-Powder Coating - CBPC. Titanium metal matrix composites reinforced with continuous $\mathrm{SiC} / \mathrm{C}$ filaments were analysed in different densification conditions. The results show that during processing, densification occurs by several mechanisms including a complex elasto-viscoplastic flow and diffusion bonding. The matrix consolidation depends on many processing conditions such as pressure and temperature, mainly. Using correct conditions of pressure and temperature, the titanium matrix composites produced by this process present a good matrix consolidation without porosity and a weak interaction between matrix and fiber. These good agreements between matrix consolidation and weak chemical interaction between matrix and fibre are obtained when pressures up to $150 \mathrm{MPa}$ and temperatures below $\beta$-transus are applied. In these conditions, supplementary heat treatments can be performed either in alpha or beta domains.
\end{abstract}

Keywords: Ti Metal-matrix composites, consolidation mechanisms, binder-powder processing

\section{Introduction}

Matrix consolidation mechanisms have been investigated in different manufacturing techniques for titanium metal matrix composites ${ }^{1-5}$. During the last decade, performance improvement of these materials has been carried out by aeronautic and aerospace industries. Based on the part shapes and the method of metal/matrix coupling, various fabrication routes have been developed in industrial field ${ }^{6-12}$ considering the fiber arrangements. According to Schüler et al. ${ }^{2}$ the influence of fiber volume fraction is slight in the range of $10-50 \%$ by volume. The only effect appears to be a shift in the maximum consolidation rate to higher levels of density. The thermal effects were analogically compared by Choo et al. $^{3}$ as a mechanical loading (hydrostatic tension), because of the lattice expansion of matrix and fiber during heating. In order to avoid the fiber degradation produced either by pressure (bended and broken) or temperature (chemical reactions), the mechanisms of matrix consolidations have been analyzed and discussed in this article based on the thermo-mechanical models. In particular, this article reports the effects of the pressure and temperature during matrix consolidation of $1 \mathrm{D}-\mathrm{Ti} / \mathrm{SiC} / \mathrm{C}$ produced by Continuous Binder-Power Coating (CBPC). As previously reported ${ }^{13}, \mathrm{CBPC}_{\text {process }}$ is an alternative fabrication route, in which the fibers are coated by impregnation of a mixing binder/powder producing a concentric binder-powder layer. After coating, the fibers are laid-up unidirectional (1-D) and hot pressed in carbide mould for matrix.

*e-mail: ras@ufpe.br

\section{Experimental Methods}

Titanium Matrix Composites (TMC) were processed by using the CBPC method. In this process a commercial silicon carbide fibers are continuously coated by a polymer binder and titanium powder mixture. The binder is a polymeric solution consisting poly-methyl methacrylate (PMMA) dissolved in acetone, at $0.20 \mathrm{~g} . \mathrm{mL}^{-1}$ composition ratio. In this process commercial Ti-powder (99.5\% at), having a sponge aspect and large grain size distribution with an average value of $100 \mu \mathrm{m}$, has been used. After acetone cleaning, the fibers were dipped into the binder solution and pulled out vertically, passing through a coating diameter limiting the binder deposited layer to about $150 \mu \mathrm{m}$. This layer regulator was specially developed for the CBPC apparatus. During these operations, both the acetone during cleaning and the polymeric solution (binder) during coating are maintained at ambient temperature. Then, the fiber is run through a container of titanium powder for gluing titanium grains on the polymeric coating (Figure 1).

During all the coating process, the fiber running speed is maintained closed to $70-75 \mathrm{~cm} / \mathrm{min}$. Finally, the coated fibers are dried. After this first step of TMC processing related to the preparation of a semi product, the coated fibers were cut into short lengths (around $42 \mathrm{~mm}$ ) and aligned (1D) in a tungsten carbide (WC) mould for composite consolidation.

Thin Ti-sheets, about $40 \mu \mathrm{m}$ thick, were placed above and below of the coated fibers, allowing initial 1-D arrangement control. The composites were processed under vacuum hot pressing (VHP) in a specific apparatus where 
the tungsten carbide tooling was placed inside a HF furnace. Under secondary vacuum, better than $10^{-5}$ Torr, heat and pressure were applied following the thermo-mechanical cycle depicted in Figure 2.

For eliminating the binder, the composite was initially heated up to $380{ }^{\circ} \mathrm{C}$ at a rate of $20^{\circ} \mathrm{C} / \mathrm{min}$ and maintained at this temperature during 30 minutes for degassing. Once the binder was eliminated at $380{ }^{\circ} \mathrm{C}$, a pressure of $20 \mathrm{MPa}$ was applied for at least 20 minutes and then relaxed. This weak pressure was progressively applied at a rate of $5 \mathrm{MPa} / \mathrm{min}$. Then, the rate of heating was maintained at $20^{\circ} \mathrm{C} / \mathrm{min}$ until the temperatures of hot pressing $(650,700$, 750 and $800{ }^{\circ} \mathrm{C}$ ). During heating, when the temperature reached $600{ }^{\circ} \mathrm{C}$, the pressure was again applied at a rate of $5 \mathrm{MPa} / \mathrm{min}$ up to 100 or $200 \mathrm{MPa}$; allowing the control of the fiber arrangement and avoiding damage or breakage of fiber. This pressure was maintained for 30 minutes in $T_{H P}$ condition, flowing creeping and consolidation of matrix grains. After hot-pressing, specimens were slowly cooled inside the furnace.

Samples for microstructural characterization were prepared following classical metallographic techniques. Different diamond liquids were used during polishing. The microstructure was observed using optical (OM) and scanning electron microscopes (SEM).

\section{Results and Discussion}

Using the coating conditions leading to a binder/powder layer of 400-420 $\mu \mathrm{m}$, after hot-pressing the TMC presents a fiber volume fraction of $14-16 \%$, depending on the

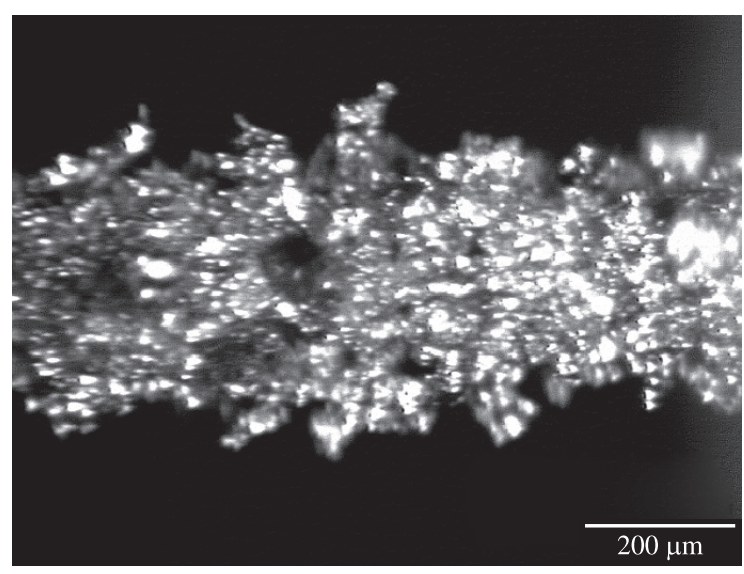

Figure 1. Binder-powder coated fiber.

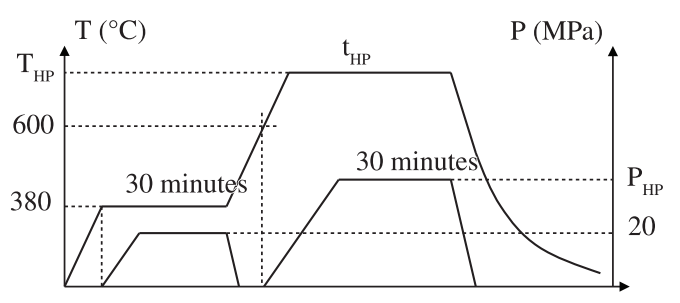

Figure 2. Thermo-mechanical cycle used to produce 1D-Ti/SiC/C by CBCP process. consolidation pressure. An increase in volume fraction can be obtained with a smaller diameter of binder layer regulator.

Particular care has to be taken during processing when the maximum pressure is applied. As a matter of fact, the fiber arrangement can be seriously disturbed because of irregular coated surfaces. During hot-pressing, the SiC-fibers were bended and broken when the pressure was rapidly applied. This damaging effect is not only observed for the highest consolidation pressures but was also commonly observed for rather smaller pressures. For instance, fiber breakage was systematically induced by pressure application at rates higher than $5 \mathrm{MPa} / \mathrm{min}$, even though the final pressure is smaller than $180 \mathrm{MPa}$. This effect can be explained by considering that in high rates of pressure increase, the isostatic compressive component of the stress field is insufficient, when compared to the stresses induced by sharp points of Ti-powder ${ }^{13-15}$. Tacking into account these preliminary considerations, rates of pressure were limited at $5 \mathrm{MPa} / \mathrm{min}$ and the maximum pressure was lowered from $200 \mathrm{MPa}$ to $150 \mathrm{MPa}$. Following the conditions previously defined ${ }^{16}$ it allowed an acceptable distribution of reinforcements to be obtained.

Results show that depending on the pressure and temperature conditions, significant porosity in matrix can be produced, particularly, in lower temperatures even if an elevated pressure is applied. For temperature of around $650{ }^{\circ} \mathrm{C}$, grains in vicinity of the fiber show that the matrix consolidation is not completely achieved (Figure 3). After 30 minutes in this hot pressing condition, the plastic flow transforms the sharp-pointed grains into equiaxed grains. Because of this, the porosity is found mainly in the grain boundaries and has an average diameter of 30 to $35 \mathrm{~mm}$. On the other hand, in zones nearby the upper surface, fiber damage is always produced by elevated pressure. Fissures can be produced both in carbon protective coating and fiber core, as has been previously shown and discussed ${ }^{16}$. If a pressure of $100 \mathrm{MPa}$ is applied during densification, the fibers are not blended or broken.

Nevertheless, the matrix is not well consolidated, even thought the temperatures increase from 650 up to $800{ }^{\circ} \mathrm{C}$. As illustrated in Figures 4 and 5, poor ameliorations were

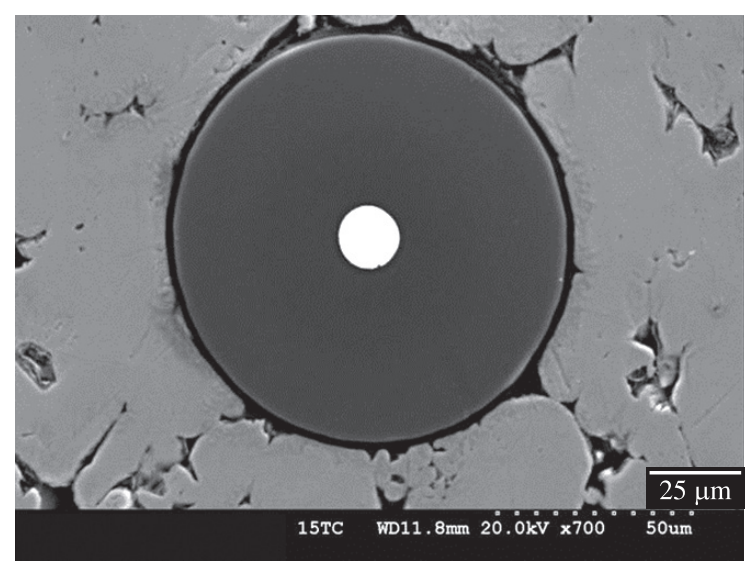

Figure 3. Microstructure of composites processed up to $200 \mathrm{MPa}$ for 30 minutes at $650{ }^{\circ} \mathrm{C}$. 


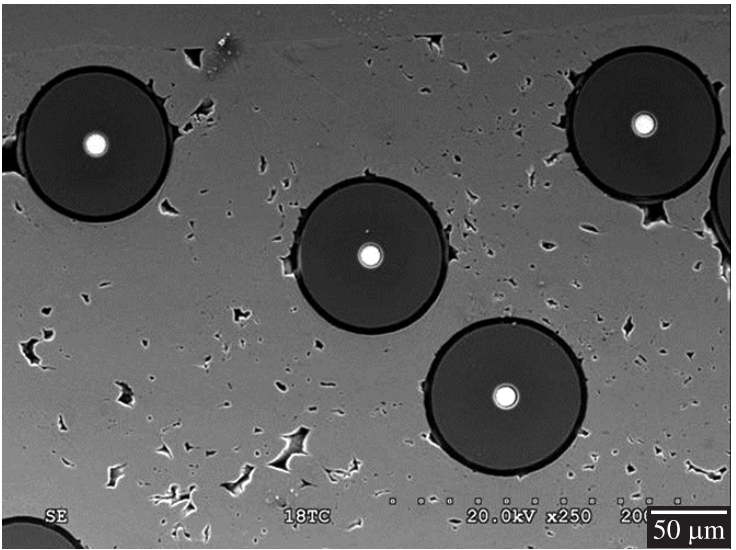

Figure 4. Microstructure of composites processed up to $100 \mathrm{MPa}$ for 30 minutes at $700{ }^{\circ} \mathrm{C}$.

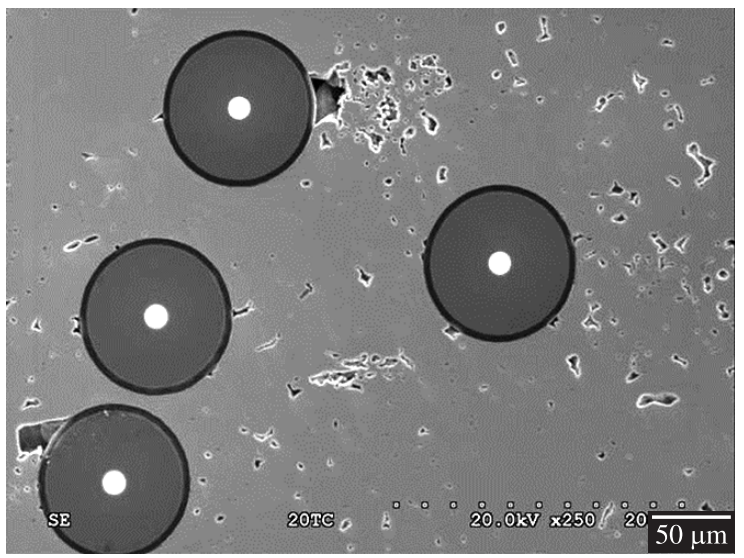

Figure 5. Microstructure of composites processed up to $100 \mathrm{MPa}$ for 30 minutes at $800{ }^{\circ} \mathrm{C}$.

produced when the temperature increased from 700 to $800{ }^{\circ} \mathrm{C}$. Porosity is always observed in the matrix. A good compromise between matrix consolidation and weak chemical reaction is produced when a pressure of $150 \mathrm{MPa}$ and temperature of $800{ }^{\circ} \mathrm{C}$ are applied during 30 minutes. Under this condition, the diffusion bonding increases producing a good matrix consolidation (Figure 6), while the chemical reactions at interface are limited to a few nanometers; as previously explained by analysis ${ }^{16}$ performed in Auger electron spectroscopy (AES).

Generally, the matrix consolidation has been described in TMC studies ${ }^{1-5}$ by using unified mechanical models, despite different mechanisms concerned; above all at the beginning of the densification cycle ${ }^{11-14}$. For TMC produced by Continuous Binder-Powder Coating, special attention must be made, particularly when heat and pressure are applied in vacuum hot pressing (VHP) for porosity elimination. Results showed that $\mathrm{SiC} / \mathrm{C}$ fibers are broken if a high pressure (greater than $200 \mathrm{MPa}$ ) is applied. In the other hand, in low pressure $(\leq 100 \mathrm{MPa})$, a poor matrix consolidation is always produced, even if the processing occurs at elevated temperature. In CBPC process, results showed that both pressure and temperature are important

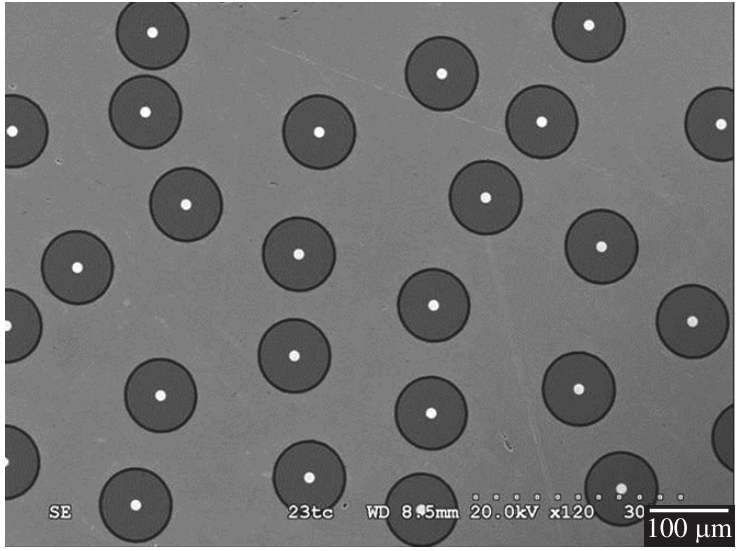

Figure 6. Microstructure of composite processed up to $150 \mathrm{MPa}$ during 30 minutes at $800{ }^{\circ} \mathrm{C}$.

parameters for matrix consolidation, contrary to the fiber-foil-fiber process in which the temperature has a less important role, as compared with the pressure ${ }^{1-2}$.

Despite of the differences between binder-powder coating and fiber-foil-fiber manufacturing conditions, the final results concerning the matrix consolidation are in agreements ${ }^{1,2,7,12-14}$. For all temperatures between 700 and $800{ }^{\circ} \mathrm{C}$ performed in CBPC process, both the plastic deformation and the diffusion bonding (as consequence) are weak and insufficient for porosity elimination, if a pressure of $100 \mathrm{MPa}$ is applied.

Using the foil-fiber-foil manufacturing technique, Osborne et al. ${ }^{7}$ explained the porosity of the matrix, hot pressed in similar condition, considering the residual stress which arises during cooling. Because of the difference in coefficients of thermal expansions between $\mathrm{SiC}$ fiber and $\mathrm{Ti}$ matrix, porosity can be formed ${ }^{7}$. Even though the interface reaction is weak, theses differences in thermal expansion cause an inherent residual stress in matrix, in both the normal and radial directions, which contributes to porosity in matrix. Choo et al. ${ }^{3}$ show that in transverse direction, particularly, the matrix and the fiber expand independently over the whole temperature range, indicating that the thermal load is not shared. Dudek et al. ${ }^{17}$ explain the voids formation (porosity in reaction zone) based only on the volume contraction produced by chemical reaction on the interfacial zones. In our manufacturing conditions, the porosity cannot be attributed to volume contraction (chemical reaction) or differences in thermal expansion. In absence of chemical reactions (see figs. 4, 5 and 6), this weak consolidation condition can only be explained by changes in the stress field during hot-pressing. When the pressure is slowly applied and reaches to $100 \mathrm{MPa}$, the sharp points of the grains contribute to plastic deformation. The local stress in these sharp points is elevated, holding the plastic flow. After a number of minutes at $100 \mathrm{MPa}$, the sharp points are fully deformed and the grains became approximately equiaxed, as shown in Figure 3. In this deformation condition, the distortion component (deviator) of the stress field tends towards zero, so the isostatic stress field becomes only the hydrostatic stress field, stopping the plastic deformation. 
C. Even et al. ${ }^{4}$ explained the behavior of matrix consolidation in similar conditions, based on model which considers the elasto-viscoplastic deformations of the matrix. It has been shown that for a same pressure and a fixed grain size, no changes in matrix densification are meaningfully produced when the temperature increases from 600 up to $700{ }^{\circ} \mathrm{C}$. The model proposed by Even et al. ${ }^{4}$ may explain how after 20 minutes of hot-pressing at $100 \mathrm{MPa}$, no changes in matrix densifications were produced. Using CBPC manufacturing technique, it was necessary an increasing of the pressure to achieve the matrix consolidation. A good compromise between pressure $(150 \mathrm{MPa})$ and temperature $\left(800^{\circ} \mathrm{C}\right)$ was obtained during matrix consolidation, without fiber degradation. In this condition, neither fiber breakages produced by pressure nor excessive chemical reaction produced by temperature were observed as previously shown ${ }^{16}$. Theses results concerning the matrix consolidation are in agreement with Schüler et al. ${ }^{2}$. Through the use of finite element model (FEM), theses authors showed that for pressure of $100 \mathrm{MPa}$ and temperature of $800^{\circ} \mathrm{C}, 30$ minutes is a critical value of time for matrix consolidation. Contrary, using a pressure of $150 \mathrm{MPa}$ at the same temperature, 30 minutes is sufficient to achieve full density (Figure 6). Because of this weak interaction fiber/matrix during CBPC process, supplementary heat treatments can be performed both in alpha and beta domains, considering the microstructure ameliorations, if a titanium alloy is used.

Experimental and theoretical results show that differences of fiber volume fractions have a little influence on the matrix consolidation, particularly in fiber-foil-fiber process. Similar results concerning fiber volume fraction can be attempted in CBPC process. Nevertheless, it

\section{References}

1. Kim TW and Lee $\mathrm{CH}$. Micro-mechanical modeling the densification behavior of titanium metal matrix composites. Composites Part A. 2004; 20:1-9.

2. Schüler SB, Derby M and Ward-Close CM. Matrix flow and densification during the consolidation of matrix coated fibres. Acta Materialia. 2000; 48(6):1247-1258. http://dx.doi. org/10.1016/S1359-6454(99)00428-0

3. Choo H, Rangaswamy P, Bourke MAM and Larsen JM. Thermal expansion anisotropy in a Ti-6Al-4V/SiC composite. Material Science \& Engineering A. 2002; 325(1-2):236-241. http://dx.doi.org/10.1016/S0921-5093(01)01463-0

4. Even C, Arvieu C, Countand B, Heintz JM and Quenisset JM. Comptes Rendus du Colloque sur les Innovations dans les Matériaux Frittées. Juillet: Poitier; 2001.

5. Nicolaou PD, Piehler HR and Saiga S. Process parameter selection for the consolidation of continuous fiber reinforced composites using finite element simulations. International Journal of Mechanical Science. 1995; 37(7):669-690. http:// dx.doi.org/10.1016/0020-7403(94)00092-X

6. Ward-Close CM, Robertson JG and Godfrey P. Metal Matrix Composites. Ed. Pergamon; 2000. vol. 3, p. 655-678.

7. Osborne D, Chandra N and Ghonem H. Interphase behavior of titanium matrix composites at elevated temperature. has already shown by Nicolaou et al. ${ }^{5}$ that the fiber redistribution, resulting from a swimming process during matrix consolidation, may cause significant degradation in mechanical properties of TMC. So, further investigations are necessary to verify the influence of the fiber distribution in $1 \mathrm{D}-\mathrm{Ti} / \mathrm{SiC} / \mathrm{C}$ composites produced by Continuous Binder-Powder Coating (CBPC).

\section{Conclusion}

Titanium Metal Matrix Composites can be produced by CBPC - Continuous Binder-Powder Coating. Pressure and temperature are the most important parameters in CBPC process during matrix consolidation. SiC/C fibers are broken if a high pressure (greater than $200 \mathrm{MPa}$ ) is applied. On the other hand, if a low pressure $(\leq 100 \mathrm{MPa})$ is applied, poor matrix consolidation is always produced, even thought the processing occurs at elevated temperature. A good compromise between pressure and temperature $(150 \mathrm{MPa}$ at $800{ }^{\circ} \mathrm{C}$ ) can be obtained during matrix consolidation, without fiber degradation produced by pressure or excessive chemical reaction produced by temperature. Considering the weak interactions matrix/fiber produced during hot-pressing, supplementary heat treatments can be performed either in alpha or beta domains without damage meaningfully the reinforcements.

\section{Acknowledgements}

Authors thankfully acknowledge Brazilian research agency $\mathrm{CNPq}$ - Conselho Nacional de Desenvolvimento Científico e Tecnológico for financial support for this work.

Composites Part A. 2001; 32(3-4):545-553. http://dx.doi. org/10.1016/S1359-835X(00)00082-8

8. Warrrier SG and Lin RY. Recent Advances. In: Froes FH and Storer J, editors. Titanium Metal Matrix Composites. Rosemont; 1995. p. 45-53.

9. Jin O and Steven Johnson W. Physical properties and life prediction of TMC at elevated temperatures. Composites Part A. 2004; 35(1):113-120. http://dx.doi.org/10.1016/j. compositesa.2003.07.003

10. Xun YW, Tan MJ and Zhou JT. Processing and interface stability of $\mathrm{SiC}$ fiber reinforced $\mathrm{Ti}-15 \mathrm{~V}-3 \mathrm{Cr}$ matrix composites. Journal of Materials Processing Technology. 2000; 102(1-3):215-220. http://dx.doi.org/10.1016/S0924-0136(00)00473-8

11. Miracle DB. Metal matrix composites - From science to technological significance. Composites Science and Technology. 2005; 65(15-16):2526-40. http://dx.doi. org/10.1016/j.compscitech.2005.05.027

12. Kromm FX, Quenisset JM, Lorriot T, Harry R and Wargnier H. Definition of a multimaterials design method. Materials and Design. 2007; 28(10):2641-2646. http://dx.doi.org/10.1016/j. matdes.2006.09.019

13. Sanguinetti Ferreira RA, Yadava YP, Arvieu C and Quenisset JM. Continuous Binder-Powder Coating for the Production of Ti/SiC/C Composites. Materials Science Forum. 2006; 530531:293-297. http://dx.doi.org/10.4028/www.scientific.net/ MSF.530-531.293 
14. Even C, Arvieu C and Quenisset JM. Powder route processing of carbon fibres reinforced titanium matrix composites. Composites Science and Tecnology. 2008; 68(6):1273-1281. http://dx.doi.org/10.1016/j.compscitech.2007.12.014

15. Segara M, Arvieu C and Quenisset JM. A new procedure of statistical approach characterization of ceramic filament fracture strength by bending tests. Engineering Mechanics. 2008; 75:4117-4126.
16. Sanguinetti Ferreira RA, Arvieu C and Quenisset JM. Effects of pressure and thermal exposure on the $\mathrm{Ti} / \mathrm{SiC} / \mathrm{C}$ composites produced by continuous binder-powder coating. Scripita Materialia. 2005; 53(3):329-333. http://dx.doi.org/10.1016/j. scriptamat.2005.04.007

17. Dubek HJ and Weber K. Voids formation in TMC processed by fibre coating. Composites Part A. 2002; 33:1705-1708. http:// dx.doi.org/10.1016/S1359-835X(02)00187-2 